\title{
Una revisión del arbitraje internacional de inversiones a la luz de la organización de la jurisdicción chilena
}

\section{International Investment Arbitration under the Chilean Jurisdictional Organization: A Review}

\author{
JOAQUÍN SCHÄFER RODRÍGUEZ
}

\begin{abstract}
Resumen
En un mundo crecientemente globalizado, el derecho ha debido incorporar nuevas figuras e instituciones, a fin de dar respuesta a las nuevas demandas que el tráfico jurídico exige. Así, el arbitraje internacional de inversiones se ha consagrado como el método idóneo para la resolución de controversias en materia de inversiones internacionales. Pese a las críticas y elogios que ha recibido, lo cierto es que su incorporación ha importado más de un desafío a nivel doctrinal. La presente investigación pretende dar una respuesta dogmática a la cuestión de la incorporación del arbitraje de inversiones en el ordenamiento nacional, a la luz del esquema de la jurisdicción chilena. Si bien el mandato constitucional indica que los llamados a cumplir con la función jurisdiccional son los tribunales establecidos por la ley, el surgimiento del arbitraje de inversiones queda en manos de los tratados internacionales suscritos y ratificados por Chile.
\end{abstract}

Palabras clave: Arbitraje internacional de inversiones; Jurisdicción; Acuerdo de Protección y Promoción recíproca de las Inversiones; Tratados Bilaterales de Inversión; Derecho internacional económico

\begin{abstract}
In an increasingly globalized world, the law has had to incorporate new figures and institutions in order to respond to the new demands in the legal trade. Thus, international investment arbitration has become renowned as the most suitable method for conflict resolution in matters pertaining to international investments. Despite the criticism and praise that it has received, its addition has certainly caused more of a challenge at a doctrinal level. This investigation intends to answer the dogmatic issue of the addition of international investments arbitration in the national legal system, under the Chilean jurisdictional framework. Although the constitutional mandate states that the courts determined by law are the ones called to carry out the jurisdictional function, the rise of investment arbitration is left in the hands of international treaties that Chile has signed and ratified.
\end{abstract}

\footnotetext{
La presente investigación se desarrolló en base a los contenidos de la Memoria "Notas sobre la configuración normativa del arbitraje internacional de inversiones en Chile. Regulación y crítica”, dirigida por el Prof. Mauricio Ríos Lagos. Agradezco los valiosos comentarios del Sr. Sebastián Chandía Olivares. Artículo recibido el 28 de abril de 2021, y aceptado para su publicación el 16 de agosto de 2021.
}

Pontificia Universidad Católica de Valparaíso, Chile (joaquin.schafer@pucv.cl). ORCID: http://orcid.org/0000-0003-4341-8098. Artículo recibido el 28 de abril de 2021, y aceptado para su publicación el 16 de agosto de 2021. 
Key Words: International investment arbitration; Jurisdiction; Reciprocal Protection and Promotion of Investments Agreement; Bilateral Investment Treaties; International Economics Law.

\section{INTRODUCCIÓN}

Frente a la globalización y a la liberalización de la economía mundial, es posible advertir que la interrelación entre los actores en el escenario internacional es cada vez más intensa. Si otrora los protagonistas eran los Estados soberanos, hoy se han incluido nuevos sujetos $\mathrm{y} / \mathrm{o}$ entes, dentro de los cuales destacan distintas empresas e inversores transnacionales, los que no conocen de fronteras ni límites espaciales.

El derecho ha debido saber responder a las nuevas exigencias que han importado el tráfico mercantil y las nuevas dinámicas internacionales. El avenimiento del arbitraje de inversiones es apreciado como parte de este fenómeno global complejo que afecta al derecho. Este surge con el objeto de dar una respuesta a unos especiales conflictos jurídicos (de inversiones) entre unos especiales sujetos (Estados soberanos e inversionistas privados).

Si bien esta figura ha sido objeto tanto de críticas, como de alabanzas, parece relevante identificar ciertas cuestiones que pueden resultar llamativas a la luz del ordenamiento jurídico interno. ${ }_{\mathrm{C}}$ Es posible afirmar que la existencia de estos tribunales arbitrales amenaza la jurisdicción interna de los Estados firmantes de los tratados de inversión? ¿Es correcto aseverar que el arbitraje internacional de inversiones cumple con una función jurisdiccional? ¿ ${ }_{\mathrm{C}}$ En qué medida es conciliable esta figura con la organización de la jurisdicción chilena?

Con el objeto de dar respuesta a las anteriores interrogantes, la presente investigación sigue una metodología dogmática e histórica, así como aspira a realizar un análisis del arbitraje internacional de inversiones, a partir del esquema jurisdiccional chileno.

Para tratar las cuestiones previamente propuestas, el artículo se estructura de la siguiente manera: en primer lugar, se realiza una revisión a la teoría de la jurisdicción (II); para lo cual se delimita su origen histórico, haciendo una breve referencia a la existencia de tribunales mercantiles en el medioevo y el posterior desarrollo doctrinal de la teoría, hasta conceptualizar a la potestad jurisdiccional como expresión de la soberanía (2.1.); enseguida, se ofrece un esquema general de la organización de la jurisdicción en Chile (2.2.). En segundo lugar, se analiza la figura del arbitraje de inversiones (III); en este sentido, se revisa su origen e incorporación en el ordenamiento nacional (3.1.); para luego realizar un distingo entre el arbitraje internacional y el doméstico (3.2.); lo anterior, con el objeto de situar al primero en el esquema jurisdiccional chileno. (3.3.). Posteriormente, se pretende dar respuesta a la cuestión de la inclusión del arbitraje de inversiones en el ordenamiento nacional (IV); siendo menester identificar a los tratados internacionales como la fuente de este método de resolución de conflictos (4.1.); para, entonces, identificar que el problema y la respuesta a la cuestión son los conflictos normativos (4.2.). Finalmente, la presente investigación ofrece algunas conclusiones al respecto $(\mathrm{V})$. 


\section{LA TEORÍA DE LAJURISDICCIÓN}

\subsection{Origen histórico y desarrollo}

Desde el surgimiento de la era moderna, se ha comprendido a la jurisdicción dentro del concepto de soberanía, entendiéndose a la primera como la potestad de aplicar el derecho de manera coercitiva en un territorio determinado. En este sentido es preciso destacar que esta concepción encuentra su origen en el pensamiento ilustrado, para el cual la jurisdicción es una función estatal, puesto que el ordenamiento jurídico y la producción normativa eran privativas del Estado.'

Ahora bien, este poder jurídico coactivo no ha estado siempre unido a la soberanía. De cierta forma, es posible señalar que la noción de jurisdicción es anterior en términos históricos. Jurisdicción viene del latín ius dicere, que puede conceptualizarse como la declaración coactiva del derecho por quien tiene la potestad. ${ }^{2}$ En la tradición romana, el iudex, o juez, no era un perito jurídico, sino más bien un lego que desempeñaba una función de arbitraje, presidiendo el arreglo de reyertas de acuerdo con fórmulas proporcionadas por el praetor. El juez no era un experto en derecho y tenía un poder muy limitado; en su caso, para consultas legales, era propio dirigirse al jurisconsulto. ${ }^{3}$

Entonces, si la expresión jurisdicción tiene un origen romano, ¿̇por qué aquello que hoy se denomina jurisdicción dista tanto de su origen? Esto viene dado por su propio devenir histórico-político. Así, durante el período de la Roma imperial, la resolución de controversias entre particulares paulatinamente empezó a quedar en manos de funcionarios públicos. Estos sí estaban versados en derecho, aunque su función principal era la de aplicar la voluntad del emperador. ${ }^{4}$ En este sentido, es posible advertir que lentamente la facultad de decidir la solución normativa aplicable a un caso se asocia en la autoridad del sentenciador.

Esta situación se mantuvo en el medioevo europeo, cobrando relevancia la figura del juez, en cuanto su poder viene amparado por la figura del rey. La expresión de la sentencia es entendida, entonces, como un pronunciamiento de justicia para un caso concreto, como la resolución de cada litigio particular con arreglo a la conciencia jurídica que el rey encarna o representa, la que se aplica finalmente al caso determinado. ${ }^{5}$ De esta forma, es posible entender que la función jurisdiccional guarda relación no solo con decir el derecho aplicable, sino también con la manifestación del poder soberano de la autoridad, con la propia concepción de justicia del monarca. ${ }^{6}$

Luego de la caída del imperio romano de occidente, surgieron en Europa pequeños reinos, cuyos monarcas lentamente fueron concentrando y centralizando su poder, a través de profundas reformas en los mecanismos de ejercicio de su poder político y gobierno. De esta forma, se empezó a consolidar una figura del Estado en que la soberanía se concentra

${ }^{1}$ Domingo (2008), p. 74.

${ }^{2}$ Domingo (2008), p. 74.

${ }^{3}$ Merryman (1980), p. 68. Para una revisión histórica del derecho romano, vid. GuZMán (2013), pp. 30-34, $56-80,113,131-139,171-172$ y 229.

${ }^{4}$ Merryman (1980), pp. 68-69.

${ }^{5}$ MARTínez (2010), p. 319.

${ }^{6}$ MarongiU (1953), pp. 705-707. 
en las manos de un monarca absoluto y se extiende sobre un territorio determinado. El rey era el depositario exclusivo del poder público y ejercía la soberanía con entera independencia, aun siendo el rey el juez supremo. Este proceso dio como resultado el afianzamiento del Estado moderno y la figura de la monarquía absoluta, las que jugaron un rol relevante en la relación del poder estatal con la soberanía y la jurisdicción.?

En este tiempo, es posible afirmar que el titular de la jurisdicción es el monarca y aun el rey es juez en su origen; ahora bien, para desarrollar esta labor, fue preciso que el monarca se dotara de funcionarios que le asistiesen en la tarea. Para esto, fue necesario que el monarca delegara sus funciones en oficiales y funcionarios, con el fin de descongestionar la administración real. De esta forma, la jurisdicción se entendió como el poder o autoridad para gobernar y poner en ejecución las leyes y, especialmente, el poder con que han sido investidos los jueces para administrar justicia en nombre del rey soberano. ${ }^{8}$ En este sentido, es posible hablar de una justicia delegada, en cuanto su administración es delegada por el monarca a sus funcionarios, administrando estos la justicia en su nombre.

Asimismo, al amparo del poder real, surgió, en algunas ciudades y Estados bajomedievales europeos, la figura de los tribunales mercantiles. Estos dicen relación con la aparición del derecho comercial, entendido como una rama separada del derecho civil, elaborado por y para los comerciantes. ${ }^{10}$ Estos mercaderes se solían agrupar en corporaciones y gremios, en virtud de los cuales crearon sus propios tribunales especiales para solucionar las controversias que se suscitaban entre ellos."

A modo ilustrativo, vale destacar el Consolat de Mar, como una institución clave para dirimir los conflictos entre mercaderes, en el contexto del comercio medieval catalán. Esta figura surgió en un momento en que los mercaderes requerían de soluciones celeras y eficaces para sus problemas, donde eran necesarios un conocimiento de la disciplina y de los usos y costumbres mercantiles; así como en un contexto en que los textos jurídicos existentes, como el código Justiniano, aparecen como insuficientes y anacrónicos. ${ }^{12}$

Los tribunales mercantiles se desarrollaron para responder a necesidades específicas del tráfico mercantil y de la navegación, así como para garantizar el respeto de los contratos que se suscribían y, en general, a la actividad que desarrollaban. Estas instituciones mercantiles dependieron de los privilegios de los monarcas, puesto que en que virtud de estos se justificaba la existencia de estos tribunales especiales para un gremio determinado. El desarrollo de esta área y la consagración de dichos privilegios vale señalar, fue producto del éxito de la alianza entre la monarquía y las familias de mercaderes que habían sostenido económicamente sus campañas militares y, por tanto, su propio poder político. ${ }^{13}$

Así las cosas, es preciso tener en consideración que, si bien proliferaron en las ciudades del mediterráneo europeo estos tribunales especiales, como fue el caso del

${ }^{7}$ BÖCKENFÖRDE (1991), pp. 26-46.

${ }^{8}$ Huesbe (1995), p. 342.

${ }^{9}$ BORDALí (2016), pp. 15-21.

${ }^{10}$ Merryman (1980), pp. 32-33.

${ }^{11}$ Miralles De ImPerial (2017), pp. 56-57.

${ }^{12}$ FerRer (1999), pp. 53-65.

${ }^{13}$ SOLdani y TANZINI (2016), p. 21. 
Consolat de Mar, estos tuvieron su razón de ser en virtud de los privilegios otorgados por el propio rey. El monarca sigue siendo el detentor de la soberanía y de la jurisdicción, un rey juez, y, en virtud de esta figura, le otorga dichas prerrogativas a un gremio determinado, como es el caso de los mercaderes y navegantes. ${ }^{14}$

Con el avenimiento de la revolución francesa, la función jurisdiccional sufrió cierta transformación, pero no perdió su estricta unión a la noción de soberanía. El cambio vino dado en cuanto a los jueces, y a la aplicación del derecho; esta ya no se asociaba a la autoridad del monarca, sino más bien a la autoridad que entrega la propia ley. ${ }^{15}$ Los revolucionarios pretendieron llevar la doctrina de separación de poderes al extremo, lo que condujo a negarles a los jueces toda función interpretativa de la ley, puesto que esta era la propia voluntad soberana manifestada. La legislación era la única encargada de guiar al juez en su labor, limitándose este a aplicarla de manera irrestricta. ${ }^{16}$

Otrora los jueces eran funcionarios del rey y administraban la justicia en su nombre, ahora carecían de dichas prerrogativas y eran personajes secundarios en el derecho. La administración de justicia era una labor que no admitía interpretaciones ni carices intermedios, debiéndose exigir al legislador la solución para cualquier problema de interpretación legal. Esto, en el entendido revolucionario de que los defectos de la ley sean subsanados manteniendo a los tribunales ajenos a la facultad de hacer leyes y, así, que el Estado se vea libre del temor a la tiranía judicial. Frente a lo poco práctico de la anterior situación, se creó un órgano gubernamental que tuviera por fin la anulación de las interpretaciones incorrectas de la ley de los tribunales: el Tribunal de Casación. Con esto se salvaguardaba la supremacía legislativa; los jueces ordinarios se veían impedidos de interpretar los estatutos jurídicos y la legislatura se eximía de dicho trabajo. ${ }^{17}$

Los revolucionarios criticaban que la sentencia de derecho haya estado durante siglos ligada a la voluntad del señor que ejercía el poder, es decir, al monarca soberano. De esta forma, si en el antiguo régimen la sentencia era un brazo del rey para manifestar su poderío, en la era moderna se hizo el esfuerzo por racionalizar el ejercicio de la jurisdicción y la administración de la justicia. En este sentido, fue preciso conceptualizar a la administración de justicia no solo como una manifestación de poderío del ente soberano, sino también como producto de un proceso racional. Así las cosas, la inseparable relación entre el derecho y el poder político condujo a una simbiosis de la justicia y la política. ${ }^{18}$

En este esfuerzo racionalizador, se fue desarrollando paulatinamente una teoría de la jurisdicción, estrechamente relacionada con la soberanía. La teoría del soberano como titular de la jurisdicción es también recogida por la filosofía política de la época. Thomas Hobbes (1588-1679), en su Leviatán, señala que el derecho de judicatura es inherente a la soberanía, ${ }^{19}$ entendiéndose a la primera como el oír y decidir de todas las controversias que puedan surgir respecto a la ley, en relación con los hechos. El inglés recuerda la importancia de esta facultad, amén de su visión práctica del Estado, en cuanto este ha surgido para

\footnotetext{
${ }^{14}$ SOLDAni y TANZINi (2016), p. 21.

${ }^{15}$ Merryman (1980), p. 69.

${ }^{16}$ Merryman (1980), p. 73.

${ }^{17}$ Merryman (1980), pp. 73-76.

${ }^{18}$ HuesBe (1995), p. 343.

${ }^{19}$ HobBes (1999), p. 27.
} 
proporcionar seguridad a quienes lo conforman y lograr cierta paz social en la población. Parece ser claro que, para Hobbes, la jurisdicción es consustancial a la soberanía. ${ }^{20}$

Si bien se dejó en claro que las nociones de jurisdicción y de soberanía no surgieron unidas, lo cierto es que hoy se entienden inseparables. Lo que se entendía por jurisdicción sufrió una transformación de la mano del devenir histórico-político europeo, lo que hizo que esta se acoplara al poder soberano del rey, o del Estado.

La jurisdicción se ha convertido en una manifestación de la soberanía, producto del esfuerzo racionalizador ilustrado, intentando superar su relación estricta con el monarca del antiguo régimen. Ahora bien, parece interesante cuestionarse este matrimonio por conveniencia: ¿debe ser la jurisdicción un poder de carácter y origen estatal? La historia indica que la respuesta no es afirmativa, que la unión entre ambas nociones vino dada por un proceso político, donde se entendió a la jurisdicción como un poder privativo de la soberanía.

Ahora bien, también es correcto afirmar que la actividad comercial siempre requirió de unas condiciones especiales para su desarrollo, el que vino dado con el surgimiento del derecho comercial en las principales urbes del mediterráneo. Los mercaderes y navegantes se agrupaban en gremios y corporaciones y, gracias a los privilegios regios, pudieron también contar con unos tribunales especiales para su actividad, que les permitió resolver sus conflictos de relevancia jurídica. Resulta ineludible soslayar los parecidos entre esta regulación y el actual comercio e inversión internacional; los que se han desarrollado con el devenir de la globalización y el aumento de los vínculos comerciales internacionales entre los Estados y entre los particulares.

\subsection{El esquema de la jurisdicción en Chile}

La concepción de la teoría de la jurisdicción asociada a la soberanía ha sido recogida por los distintos ordenamientos que forman parte de la tradición jurídica continental. Chile no constituye la excepción. Lo anterior, dado que la Constitución Política de la República (CPR) afirma que el ejercicio de la soberanía se realiza por el pueblo a través del plebiscito y de elecciones periódicas, así como también por las autoridades que esta establece (art. Quinto, i. I, CPR). En este sentido, en su capítulo VI, el texto constitucional establece como una de esas autoridades a los tribunales establecidos por la ley. ${ }^{21}$ De esta forma, la teoría de la jurisdicción chilena se enmarca, a su vez, en esta visión acoplada a la soberanía estatal.

Doctrinalmente, es posible definir la función jurisdiccional como aquella función estatal que tiene por fin el agotamiento del componente jurídico de un conflicto; este agotamiento, se entiende, tanto desde la perspectiva de la cosa juzgada, como desde la posibilidad de la aplicación de coacción, con el propósito de concretar dicha decisión. ${ }^{22}$

Pese a que la Constitución no ofrece un concepto de jurisdicción, esta indica que: "[la] facultad de conocer de las causas civiles y criminales, de resolverlas y de hacer ejecutar lo juzgado, pertenece exclusivamente a los tribunales establecidos por la ley" (art. 76 i. I, CPR). A partir de la anterior disposición constitucional, la doctrina ha entendido que existe una suerte de referencia a la jurisdicción. De esta forma, se ha dicho que la Carta

\footnotetext{
${ }^{20}$ Huesbe (1995), p. 342.

${ }^{21}$ Colombo (1968).

${ }^{22}$ AldunAte (1995), p. 16.
} 
Fundamental, por un lado, hace referencia a los momentos que importa la actividad jurisdiccional (conocer, resolver y ejecutar) y, por el otro, señala que esta recae exclusivamente en los tribunales establecidos por la ley. ${ }^{23}$

Tal como se advirtió, una interpretación del texto constitucional permite afirmar que el ejercicio de la jurisdicción se encuentra reservado de manera exclusiva a los tribunales establecidos por la ley. En este sentido, es posible preguntarse cuál es el alcance de dicho mandato constitucional, en atención a dilucidar cuáles son aquellos órganos encargados de ejercer dicha potestad. La doctrina ha señalado que esta actividad no se encuentra vinculada a un órgano estatal determinado, sino que basta con que dicha función sea consagrada a través de la ley.

Amén de esta situación, se ha dicho que en Chile no existe un poder judicial, puesto que no es posible hablar del poder judicial como un poder unitario. En este sentido, cuando se hace referencia al poder judicial en Chile, este funciona como una abreviatura para hablar de los jueces y tribunales existentes. No es el poder judicial el encargado de cumplir con la función jurisdiccional, sino cada tribunal por separado. ${ }^{25}$

Ahora bien, iforman parte del poder judicial todos los tribunales establecidos por la ley? No necesariamente, puesto que son parte de este grupo solo los tribunales ordinarios, es decir, aquellos que se encuentran regulados por un mismo estatuto orgánico: el capítulo VI de la Constitución y el Código Orgánico de Tribunales (COT). ${ }^{26}$ De esta forma, es posible encontrar en Chile también otros tribunales, que no solo se encuentran fuera del poder judicial, sino que se asocian a otros poderes, como el ejecutivo o legislativo. ${ }^{27}$

En este sentido, el texto constitucional indica que una ley orgánica constitucional será la encargada de determinar la organización y atribuciones de los tribunales necesarios para: "la pronta y cumplida administración de justicia en todo el territorio de la República" (art. 77 i. I, CPR). Así, el COT enuncia cuáles son los tribunales a los que les corresponderá el conocimiento de dichos asuntos e indica cuáles forman parte del poder judicial, ora como tribunales especiales, ora como ordinarios; esto, sin perjuicio de las excepciones que establezcan la Constitución y las leyes (art. Quinto i. I, COT).

En atención a lo dicho, parece ser que el constituyente no toma partido por qué tipo de órganos son los encargados de cumplir con la función jurisdiccional. Lo anterior, puesto que no solo es posible encontrar tribunales fuera del poder judicial, como es el caso de los Tribunales Ambientales, sino también existen tribunales que, en cuanto a su orgánica, se asocian a otros poderes del Estado, como, por ejemplo, el Senado, cuando conoce como tribunal en los casos de acusaciones políticas (art. 53, numeral primero, CPR). ${ }^{28}$

Así las cosas, parece correcto afirmar que, si bien la potestad jurisdiccional se encuentra consagrada en la Constitución, la institucionalidad de esta viene dada por la ley,

\footnotetext{
${ }^{23}$ LARROUCAU (2020), pp. 29-31.

${ }^{24}$ Aldunate (1995), pp. 16-17.

${ }^{25}$ ATRIa (2004), pp. 134-135 y BORDALí (2013), pp. 611-612.

${ }^{26}$ BORDALÍ (2009), p. 226.

${ }^{27}$ BORDALí (2009), pp. 215-216.

${ }^{28}$ BORDALÍ (2009), p. 226.
} 
que es la encargada de crear y establecer a los tribunales, así como de atribuirles la función jurisdiccional. ${ }^{29}$ A partir de lo anterior, es posible aseverar que cualquier órgano autorizado por la ley para resolver asuntos de relevancia jurídica es un tribunal de justicia. En atención a lo dicho, pueden ejercer jurisdicción los tribunales de justicia, los órganos legislativos o aquellos que formen parte de la administración del Estado, en la medida en que estos se encuentren habilitados por la ley. ${ }^{30}$

\section{ARBITRAJE INTERNACIONAL DE INVERSIONES}

\subsection{Consagración en Chile}

Con el paso del tiempo, Chile gradualmente ha incorporado en su legislación interna el arbitraje internacional como método de resolución de controversias de una especial naturaleza: comercial y de inversiones. En este sentido, es posible afirmar que esta institución opera en atención a los sujetos que intervienen en el asunto de relevancia jurídica (arbitraje comercial internacional), o dada la naturaleza del asunto mismo (arbitraje de inversiones).

En un sentido histórico, a partir de fines de la segunda mitad del siglo XX, Chile ha implementado una serie de reformas macroeconómicas ${ }^{31}$, las que han transformado de manera irreversible sus políticas comerciales y de inversión ${ }^{32}$; ahora bien, estos cambios fueron también replicados en el ámbito jurídico. Lo anterior, en el marco en que en Chile existía una legislación tradicional que no reconocía la sumisión a jurisdicciones o legislaciones extranjeras; asimismo, esta miraba con suspicacia las inversiones internacionales, dados los riesgos jurídicos y diplomáticos que podrían traer aparejadas (doctrinas Calvo y Drago). ${ }^{33}$

En los países latinoamericanos, entre ellos Chile, imperaba la doctrina Calvo. Esta puede conceptualizarse como una doctrina de carácter panamericana, que establece que los extranjeros deben realizar sus reclamaciones jurídicas de acuerdo con la jurisdicción local, es decir, someterse a los tribunales nacionales y evitar recurrir a la protección e intervención diplomática, ${ }^{34}$ así como a presiones del Estado del que son nacionales. ${ }^{35}$

\footnotetext{
${ }^{29}$ BORDALÍ (2009), pp. 216-217.

${ }^{30}$ Bordalí (2008), pp. 209-210. Asimismo, en este sentido vid. BORDAlí (2016), pp. 63-94.

${ }^{31}$ HARVEY (2005), pp. 7-9.

${ }^{32}$ HuneEus (2007), pp. 199-204 y 271-306.

${ }^{33}$ Formulada en 1902, por el ministro de relaciones exteriores argentino, Luis María Drago (1859-1921). Esta rechaza la figura de la protección diplomática y niega el cobro por la fuerza de las deudas contraídas por los Estados. En este sentido, vid. TAMBURINI (2002), pp. 85-88.

${ }^{34}$ La protección diplomática consiste en la acción que un Estado ejerce, por medio de la diplomacia u otros medios de solución pacífica, para invocar la responsabilidad internacional de otro Estado, con ocasión de un perjuicio causado por un hecho internacionalmente ilícito a una persona nacional del primer Estado, con el objeto de hacer valer dicha responsabilidad. Esta es considerada un derecho de los Estados. Para una revisión de la protección diplomática, vid. VARGAS (2017), pp. 472-481 y PASTOR (2013), pp. 247-249.
}

${ }^{35}$ Tamburini (2002), pp. 82-84. Como reacción a esta situación, surgió la cláusula Calvo, según la cual el inversor foráneo debe celebrar con el Estado receptor un contrato por el cual convienen que las controversias jurídicas suscitadas, serán resueltas únicamente por los tribunales competentes del Estado, de conformidad con su derecho y no podrán dar lugar a ninguna protección diplomática o reclamación internacional. Con 
Con el objeto de implementar dichas reformas económicas en el ordenamiento chileno, fue necesaria una paulatina apertura del Estado y su sistema económico, en orden a convertirse en un polo de inversión en la región. El impacto económico producido por la apertura del comercio y las inversiones, hicieron necesaria la adaptación del ordenamiento jurídico nacional a esta nueva realidad. ${ }^{36}$

Este fue el comienzo de la consagración en Chile de un sistema político neoliberal, que propende a la inversión privada, ora nacional, ora internacional; así como a la liberalización de la economía. ${ }^{37}$ Se ha dicho que este proceso fue inaugurado con la promulgación del Decreto Ley № 600 de 1974, también denominado ley sobre inversión extranjera. Como su nombre lo vaticina, este tenía por objeto incentivar la inversión de origen internacional en el país.

Vale destacar que este decreto fue derogado en una de las últimas reformas tributarias (Ley № 20.780), y su regulación fue sustituida por la Ley № 20.848. Es menester señalar que este cuerpo normativo estableció un nuevo marco para la inversión extranjera directa en Chile, así como creó una nueva institucionalidad al respecto: InvestChile. Dicho texto legal entró en vigor el 1 de enero de 2016, y suplió la derogación del anterior decreto ley.

En adición a lo anterior, durante la década de 1990, Chile aprovechó los cambios en su política interna y apertura de su sistema económico, los que le permitieron asumir un rol protagónico en el concierto internacional. En este sentido, se ha desarrollado un intenso proceso de negociación y suscripción de acuerdos bilaterales sobre inversión, iniciando una etapa importante en su política de inserción en el panorama económico internacional. ${ }^{38}$ En el plano bilateral, Chile ha suscrito más de treinta acuerdos para la promoción y protección recíproca de las inversiones (APPI) o tratados bilaterales de inversión (TBI), con distintos países de los cinco continentes. ${ }^{39}$

Estos APPI pueden conceptualizarse como tratados internacionales celebrados por dos o más Estados, en virtud de los cuales estos se obligan a asegurar a los inversionistas de la otra parte, y a sus inversionistas, un trato no discriminatorio por parte del ordenamiento jurídico del Estado receptor de dicha inversión. Adicionalmente, dichos tratados contemplan el establecimiento de un mecanismo de solución de controversias

todo, el asunto ha perdido en la actualidad la importancia que tuvo décadas anteriores. Hoy la tendencia, fuera de controlar las inversiones, es estimularlas y proporcionar la seguridad jurídica necesaria. Para una revisión de la discusión, vid. VARGAS (2017), pp. 481-483; PASTOR (2013), pp. 247-252 y BROWNLIE (2008), pp. 545-546.

\footnotetext{
${ }^{36}$ BigGS (2007), pp. 351-360 y GUERRERO (2021), pp. 539-544.

${ }^{37}$ Carrillo (2010), pp. 145-154. En este sentido cfr. LARraín \& VerGara (2001), pp. 69-108.

${ }^{38}$ LOPEANDÍ́ (2001), p. 17.

${ }^{39}$ Campusano \& BOLAdO (2015), pp. 272-273 y MAHU y ROJAS (2016), p. 10.
} 
entre inversionistas y el Estado receptor, ${ }^{40}$ así, se suele establecer el sometimiento de las disputas a un panel arbitral internacional.

En atención a lo expuesto, es posible afirmar que el arbitraje de inversiones recuerda, a grandes rasgos, a los tribunales mercantiles del medioevo europeo. Lo anterior, dado que constituyen casos en que se abstraen de la justicia ordinaria ciertos conflictos de relevancia jurídica, siendo esto amparado por el poder político del momento. Ahora bien, ya no se trata de un monarca, cuyo poder político pende de una alianza con el gremio de comerciantes, sino que es el caso de un Estado que, con el objeto de promover proyectos de desarrollo económico en su territorio, cede estas prerrogativas a unos especiales sujetos: los inversores.

Con todo, es menester considerar el distingo de esta figura con el arbitraje comercial internacional, ya que en esta última el vínculo histórico de estos tribunales, no dice relación solo con la naturaleza del conflicto, sino también en atención con las partes que se enfrentan: comerciantes. Así y todo, si bien en el arbitraje de inversiones las partes son siempre, por un lado, un Estado, y, por el otro, un inversor privado, el vínculo con esta figura histórica se relaciona derechamente con la naturaleza del conflicto: la inversión. ${ }^{42}$ Así parece necesario apreciar esta figura como una respuesta institucional a unos especiales conflictos que tienen lugar en el concierto internacional, en atención al crecimiento de las relaciones económicas y comerciales entre los Estados y distintos sujetos y/o entes.

\subsection{Distinción del arbitraje doméstico}

Dentro del esquema de la jurisdicción y de los tribunales establecidos por la ley en Chile, es plausible hacer referencia al arbitraje. Los árbitros son uno de los tribunales que menciona la ley, los que pueden resolver conflictos civiles que se promuevan entre las partes (arts. 5 y 222, COT).

Ahora bien, es posible afirmar que en el derecho chileno se pueden encontrar dos clases de arbitraje: nacional, e internacional. Esta distinción tiene sentido en cuanto estos se encuentran reglados en distintos cuerpos normativos, así como pretenden regular distintos sujetos y actividades, además de que tienen una relación distinta con el ordenamiento jurídico nacional.

a) El arbitraje nacional, o doméstico, encuentra sustento legal en la propia legislación nacional. Así, el juicio arbitral se encuentra regulado como un juicio especial (arts. 628 a

\footnotetext{
${ }^{40}$ A modo ilustrativo, el APPI suscrito entre Chile e Islandia establece, en su artículo octavo, que las controversias entre un inversionista y una parte contratante podrán ser resuelta, a elección del inversionista por: a) el tribunal competente de la parte contratante en cuyo territorio se hubiere efectuado la inversión, b) el arbitraje conforme al Convenio del CIADI, o c) el arbitraje conforme al Reglamento de la CNUDMI.

${ }^{41}$ LOPEANDÍA (2001), pp. 17-18 y MujICA \& Rivera (2018), pp. 9-10. Para una revisión del desarrollo internacional de los APPI, así como de sus nuevas tendencias, vid. SORNARAJAH (2010), pp. 172-235.

${ }^{42}$ La noción de inversión implica, siguiendo el test Salini, los siguientes elementos: un volumen de contribución, una cierta duración de la relación contractual, la presencia del factor riesgo para el inversionista, y una contribución al desarrollo económico del Estado receptor de dicha inversión. Ahora bien, no cualquier relación contractual puede ser catalogada de inversión; es posible que existan contratos entre inversionistas y el Estado receptor que no constituyan inversión, sino que hagan referencia solo a relaciones comerciales entre ellos. En este sentido, las controversias suscitadas también podrán ser resueltas por el arbitraje, pero no de inversiones, sino por el comercial internacional. Para una revisión de la noción de inversión, vid. MEREMINSKAYA (2010), pp. 39-40 y LIM et al. (2018), pp. 210-231.
} 
644, CPC), al igual que la figura de los jueces árbitros (arts. 222 a 243, COT). Esta clase de arbitraje dice relación con asuntos entre nacionales y que tienen lugar dentro del territorio de la República; aun, en el caso chileno, se dice que el juicio arbitral importa una jurisdicción extraordinaria de carácter público. ${ }^{43}$

b) Por otro lado, el arbitraje internacional dice relación más bien con una herramienta de solución de controversias, antes que con el ejercicio de una potestad jurisdiccional. Se dice que el vínculo entre el arbitraje internacional y el ordenamiento jurídico se reduce a aspectos residuales; un árbitro, en esta materia, no administra justicia en nombre de ningún Estado, dado que su poder viene dado por el acuerdo entre las partes. El procedimiento arbitral internacional es sumamente respetuoso de la autonomía de las partes, dado que su reglamentación es escueta, y deja en manos de los árbitros y las partes la conducción del procedimiento.

Según algunos autores, es imprescindible reconocer el carácter sui generis del arbitraje internacional, con el propósito de evitar que se traspasen a él los conceptos y doctrinas desarrolladas en el ámbito del arbitraje doméstico. ${ }^{44}$ Como se previno, su regulación no es tan detallada como en el caso del arbitraje nacional, pero como institución, el arbitraje comercial internacional se encuentra reconocido en la ley № 19.971 y, por otro lado, el arbitraje de inversiones está regulado en los tratados internacionales suscritos y ratificados por Chile.

\subsection{El arbitraje internacional de inversiones en el esquema de la jurisdicción}

La Constitución Política de la República no indica la naturaleza o calidad del ente llamado a resolver un asunto de naturaleza jurídica. De acuerdo con la fórmula que ocupa el artículo 76, la jurisdicción recae en todo tribunal de justicia establecido por la ley. Lo anterior, salvo casos en que la propia Carta Fundamental reserva una materia a un tribunal especial, como es el caso del Tribunal Constitucional (capítulo VIII, CPR). ${ }^{45}$

Asimismo, ya se recordó que en el ordenamiento jurídico nacional existen órganos que se asocian a otros poderes del Estado, que detentan la potestad jurisdiccional y son tribunales establecidos por la ley en los términos que la Constitución indica. Por otro lado, el arbitraje internacional, en especial de inversiones ${ }^{46}$ no se encuentra regulado en la legislación nacional. Todo lo contrario, dado que el arbitraje de inversiones, entendido como el método de resolución de controversias jurídicas entre inversionistas extranjeros y el Estado, surge de los distintos tratados internacionales suscritos y ratificados por Chile. Como se explicó anteriormente, el Estado paulatinamente incorporó este sistema de tribunales de inversiones en su ordenamiento jurídico, como parte de la política

\footnotetext{
${ }^{43}$ Mereminskaya (2006), pp. 98-105.

${ }^{44}$ Mereminskaya (2006), pp. 105-106.

${ }^{45}$ BORDALÍ (2009), p. 217.

${ }^{46} \mathrm{Si}$ bien el arbitraje comercial internacional se encuentra en una situación similar, es posible encontrar leyes que lo regulen, como la ley № 19.971 de 2004. En este sentido, vid. VÁsQUEZ (2005).
} 
internacional asumida por el país, en orden a posicionarse como un polo atractivo de inversión extranjera en la región latinoamericana. ${ }^{47}$

$\mathrm{El}$ arbitraje de inversiones surge a partir de los tratados internacionales en materia económica, siendo la regla general los APPI. Con todo, estos no son los únicos instrumentos internacionales que incorporan el arbitraje internacional de inversiones. Lo anterior, dado que Chile ha ratificado más de una veintena de acuerdos comerciales con capítulos relativos a inversiones. ${ }^{48}$

A modo ilustrativo, vale destacar el Acuerdo de Libre Comercio (ALC) entre la República de Chile y los Estados Unidos Mexicanos. Dicho tratado dedica su capítulo 9 a las inversiones y establece la facultad para el inversor extranjero ${ }^{49}$ de someter sus reclamaciones jurídicas a un panel arbitral, según las reglas del Centro Internacional de Arreglo de Diferencias Relativas a Inversiones (CIADI) o de la Comisión de las Naciones Unidas para el Derecho Mercantil Internacional (CNUDMI) (art. 9-21, ALC ChileMéxico).

Ahora bien, a diferencia del arbitraje doméstico o del comercial internacional, el de inversiones no surge, por regla general, de un contrato o compromiso entre las partes. $\mathrm{El}$ arbitraje de inversiones aparece regulado en las convenciones internacionales, tanto multilaterales, como bilaterales, suscritas y ratificadas por los Estados. ${ }^{50}$

A modo ilustrativo, el acuerdo suscrito entre Chile y España sigue esta lógica: toda controversia relativa a las inversiones, entre uno de los Estados contratantes y los inversionistas nacionales del otro Estado, deberá ser sometida a la jurisdicción nacional o al arbitraje internacional, a elección del inversionista. En caso de que este último se decante por el arbitraje, nuevamente podrá elegir entre someterse al CIADI o a un tribunal arbitral ad hoc, de acuerdo con las reglas de la CNUDMI (art. Décimo, APPI Chile-España). La misma fórmula sigue el acuerdo de inversiones celebrado con Italia (art. Noveno, APPI Chile-Italia). El tratado de inversiones suscrito con Francia también incorpora esta cláusula, pero con la salvedad de que el único tribunal arbitral admisible es el establecido por el Convenio CIADI (art. Octavo, APPI Chile- Francia).

En el sistema de tribunales de inversiones vale destacar la facilidad para el reconocimiento y ejecución del laudo que resulte del juicio arbitral. Ahora bien, es posible distinguir entre el arbitraje seguido ante el CIADI y los otros procedimientos arbitrales.

a) Los Estados parte del Convenio CIADI deben reconocer el carácter obligatorio del laudo y deben ejecutar dentro de sus territorios las obligaciones pecuniarias que emanen de este, tal como si se tratase de una sentencia firme dictada por un tribunal nacional (arts.

\footnotetext{
${ }^{47}$ En cifras de la Comisión Económica para América Latina y el Caribe (CEPAL), en el año 2020, Chile se ubicó como el tercer país receptor de inversión extranjera directa en la región, superado solo por Brasil y México. CePAL (2021), p. 81.

${ }^{48}$ SUbSECRETARÍA de Relaciones ECONÓMICAS INTERNACIONALES (2021).

${ }^{49} \mathrm{Si}$ bien los propios tratados internacionales son los encargados de proporcionar una definición de inversor extranjero, esta difiere en atención al tratado en cuestión. Asimismo, para efectos de dilucidar si una persona (natural o jurídica) cumple tal calidad, es menester cumplir con ambos requisitos: ser un inversor y ser nacional del Estado con que Chile suscribió el APPI o ALC. Para una revisión del concepto de inversor extranjero, vid. PASCuAL-Vives (2019), pp. 47-108. Cfr. DOlZER \& SCHREuer (2008), pp. 46-59; MAHU \& ROJAS (2016), pp. 21-24 y SORNARAJAH (2010), pp. 323-331.
}

${ }^{50}$ LIM et al. (2018), pp. 87-88. 
53 y 54, Convenio CIADI). ${ }^{51}$ De esta forma, vale destacar que la obligación de cumplir el laudo es una obligación internacional que surge del propio Convenio. ${ }^{52}$

b) Si el arbitraje no es conforme a las reglas del CIADI, en un procedimiento ora ad hoc, ora institucional, el laudo que emane del tribunal arbitral debe ser reconocido y ejecutado siguiendo las reglas de la Convención de las Naciones Unidas sobre el Reconocimiento y la Ejecución de las Sentencias Arbitrales Extranjeras de 1958.

En atención a lo expuesto, cabe cuestionarse si los paneles arbitrales de inversión son tribunales establecidos por la ley, en los términos en que la Constitución indica. Esta regula la institucionalidad jurisdiccional y establece que los llamados a cumplir con esta función son los tribunales establecidos por la ley. Ahora bien, ¿cuál es la situación del arbitraje de inversiones? Este no se encuentra regulado por ley, sino por los tratados internacionales suscritos y ratificados por Chile, ora multilaterales, ora bilaterales.

Así las cosas, la pregunta está orientada a identificar si el sistema de tribunales de inversión es un tribunal arbitral establecido por la ley. Los tratados internacionales no son leyes y tampoco tienen el mismo rango normativo de estas; por lo anterior, es necesario revisar cuál es el rol de estos en el ordenamiento jurídico nacional, así como en la jerarquía de fuentes. En este sentido, una posible respuesta a esta interrogante viene dada por los conflictos normativos en el sistema jurídico, en atención a dilucidar el rango normativo que ostentan los acuerdos internacionales en materia de inversiones suscritos y ratificados por el Estado de Chile.

\title{
IV. UNA RESPUESTA A LA CUESTIÓN
}

\subsection{Fuente del arbitraje internacional de inversiones}

Si el arbitraje de inversiones surge a partir de los tratados internacionales, una cuestión relevante consiste en identificar cómo aplicar y entender estos instrumentos normativos a la luz del ordenamiento jurídico nacional. La entrada en vigor, en el plano internacional, de un tratado viene dada por el acto jurídico por medio del cual el Estado hace constar su voluntad de obligarse por el tratado, el que es conocido como la ratificación. $^{53}$ Vale destacar que esta función recae en la figura del Presidente de la República (art. 32, $\mathrm{N}^{\circ} 15, \mathrm{CPR}$ ). Si bien lo anterior no suscita mayor discusión, el asunto queda pendiente en cuanto a su entrada en vigencia en el derecho doméstico. ${ }^{54}$

\footnotetext{
${ }^{51}$ BungenberG \& Reinisch (2020), pp. 156-160. Cfr. FernándeZ (2009), p. 22.

${ }^{52}$ LIM et al. (2018), pp. 448 y 452-459.

${ }^{53}$ DieZ De Velasco (2017), p. 164. Cfr. PASTOR (2013), pp. 109-111.
}

\begin{abstract}
${ }^{54}$ Tradicionalmente, en atención a la cuestión de la incorporación del derecho internacional al ordenamiento jurídico interno, los autores se han escindido entre quienes defienden la teoría dualista y quienes se decantan por la concepción monista. Los primeros argumentan que el derecho internacional y el derecho doméstico son sistemas jurídicos independientes y separados, tienen fuentes distintas y no pueden ser confundidos; por lo cual, no puede plantearse un conflicto entre ellos. Por el otro lado, los monistas arguyen la unidad esencial de todos los ordenamientos jurídicos, todos las cuales dependen de un orden jerárquico riguroso y en el cual las normas del derecho interno se encuentran subordinadas a las del derecho internacional. Ahora bien, vale tener en cuenta que, si bien ninguna de las dos teorías ha sido plenamente aceptada, tanto la práctica de los Estados, como el desarrollo doctrinal, se han mostrado favorables al monismo. Para una revisión de la discusión, vid. VARGas (2017), pp. 183-189; PASTOR (2013), pp. 168-169; Diez De VeLaSCO (2017), pp. 242-243 y BROWNLIE (2008), pp. 31-33.
\end{abstract}


La Constitución no regula la posición jerárquica de los tratados internacionales en el ordenamiento jurídico nacional, ni su rango normativo. Si bien existe una asimilación de los acuerdos a la ley, este es de mediano alcance, sin extenderse a los efectos normativos del tratado. ${ }^{55}$ Los autores han discutido en torno a si entre los propios tratados internacionales suscritos y ratificados por Chile existe cierta jerarquía. En este sentido, es razonable considerar una preeminencia respecto de aquellos que versen sobre derechos humanos, lo que aún no se encuentra exento de debate. ${ }^{56}$ Con todo, la inversión internacional no es entendida como un derecho humano, así que los APPI y ALC se excluyen de la discusión ${ }^{57}$.

Frente a esto, cierta doctrina ha reconocido que la única fuente que permite reconocer la función normativa del texto de un tratado en el derecho nacional es el decreto promulgatorio del tratado del Presidente de la República, así como la orden contenida en este, en cuanto ordena dar cumplimiento al tratado. ${ }^{58}$ Lo anterior, lógicamente seguido de la publicación del decreto en el Diario Oficial.

Es relevante tener en consideración una distinción recogida tanto por la doctrina, como por la jurisprudencia constitucional, que diferencia entre tratados internacionales autoejecutables [self executing] y no autoejecutables [non self executing]. El criterio para distinguir unos de otros radica en si las disposiciones de un tratado pueden ser aplicadas por el órgano jurisdiccional, sin la necesidad de un acto normativo previo que permita dar contenido a las obligaciones del acuerdo. Ahora bien, esta distinción no permite afirmar que en el segundo caso pierde fuerza la normatividad de un tratado; este sigue siendo vinculante. ${ }^{59}$

En atención a la anterior distinción, los autores han indicado que los TBI son autoejecutables en el derecho chileno, ${ }^{60}$ reconocimiento que también es extensivo a las disposiciones relativas a inversiones extranjeras en los ALC ratificados por Chile.

Ahora bien, es necesario precisar que el carácter autoejecutable de un APPI se predica respecto de cada precepto en particular y no del texto del tratado internacional en bloque. De esta forma, se ha dicho que las cláusulas relativas al trato nacional no discriminatorio y a la protección frente a expropiaciones, directas o indirectas, son plenamente ejecutables en el derecho doméstico. Misma suerte corren las cláusulas paraguas. ${ }^{61}$

\footnotetext{
${ }^{55}$ AldunATE (2010), pp. 192-197.

${ }^{56}$ MÜLLer (2015), pp. 506-511.

${ }^{57}$ MONTT (2005), p. 41.

${ }^{58}$ Aldunate (2010), p. 198. En este mismo sentido, vid. VARGaS (2017), pp. 202-203.

${ }^{59}$ Aldunate (2010), pp. 201-202.

${ }^{60}$ MONTT (2005), pp. 28-36 y 41-47.

${ }^{61}$ MONTT (2005), pp. 43-45.
} 
Por último, es menester tener en consideración que el ejercicio interpretativo de un tratado internacional dista en gran medida de un texto legal ${ }^{62} \mathrm{o} \mathrm{constitucional}^{63}$. Interpretar implica precisar el sentido y alcance de un texto jurídico. Con este objeto, la Convención de Viena, suscrita por Chile en 1969 y en vigencia desde 1981, ha formulado ciertas reglas, en sus artículos 31 y 32, las que han sido respetadas por la práctica de los Estados y sentado precedentes judiciales ${ }^{64}$.

A la luz de las disposiciones de la Convención, los autores han señalado, grosso modo, que los elementos primordiales para esta tarea son: el sentido corriente de los términos, el contexto, el objeto y el fin del tratado, el acuerdo entre las partes, la conducta de estas y las reglas del derecho internacional ${ }^{65}$. Estos elementos deben analizados a la luz de cada tratado internacional particular; por ejemplo, en atención a los APPI y TBI, parece lógico concluir que su objeto y fin es la promoción y protección de las inversiones.

\subsection{Los conflictos normativos}

Teniendo a la vista que los tratados en materia de inversión constituyen una fuente de derecho en el ordenamiento interno, así como sus disposiciones resultan autoejecutables, cabe preguntarse acerca de los posibles conflictos normativos que pueden surgir en relación con otros textos jurídicos.

A modo ilustrativo, es posible que Chile suscriba un APPI que pugne con algunas disposiciones de la ley № 20.848, por ejemplo, en cuanto a la definición de inversor que entrega. Frente a esta cuestión, es necesario revisar si los criterios clásicos de solución de conflictos normativos entregan una respuesta a esta interrogante, a saber: los principios de jerarquía, temporalidad y especialidad.

a) El principio de jerarquía no parece apropiado para resolver el conflicto, en tanto carece de un sustento positivo en el cual pudiera fundarse. Por otro lado, el principio de jerarquía dice más bien relación con la preeminencia de la Constitución por sobre las demás fuentes del derecho ${ }^{66}$. Esto, dado que la Carta Fundamental es la encargada de establecer la jerarquía de las fuentes del derecho y regular las formas de producción de las normas jurídicas ${ }^{67}$.

Así y todo, vale tener en consideración las distintas posturas doctrinales en cuanto al rango normativo de ciertos tratados internacionales. En este sentido, es posible advertir dos interpretaciones. Por un lado, cierta doctrina ha sostenido que los tratados que versen sobre derechos humanos tienen jerarquía constitucional, en atención a lo dispuesto por el

\footnotetext{
${ }^{62}$ A grandes rasgos, en el derecho nacional se recurre a las reglas del Código Civil para la interpretación legal. Estas se encuentran contenidas en los arts. 19, 20, 21, 22, 23 y 24 del Código. Para una revisión dogmática de estas reglas, vid. GUZMÁN (1992), pp. 67-81.

${ }^{63}$ En la hermenéutica constitucional, hay autores que afirman que es necesario establecer el estándar admisible de una interpretación constitucional, el que viene dado por la plausibilidad. Esto, en atención a que la Constitución no es un texto jurídico corriente, sino también uno de carácter político e histórico. Para una revisión de las reglas de interpretación constitucional, vid. ALDUNATE (2002), pp. 261-262.
}

${ }^{64}$ VARGaS (2017), pp. 142-146. Cfr. SHaW (2008), pp. 932-938 y BroWnlie (2008), pp. 631-632.

${ }^{65}$ Pastor (2013), p. 114. Cfr. Diez de Velasco (2017), pp. 205-209.

${ }^{66}$ AldunATE (2010), pp. 205-208.

${ }^{67}$ HeNRÍQUeZ (2008), pp. 75-76. 
artículo quinto i. II de la Constitución ${ }^{68}$. Por el otro, hay quienes postulan que dichos instrumentos tienen rango de ley y una jerarquía normativa claramente inferior a la Constitución; lo anterior, fundamentalmente, porque se someten, en lo pertinente, a los trámites propios de una ley (arts. 54, $\mathrm{N}^{\circ} 1$, i. I y $66 \mathrm{CPR}$ ), así como pueden ser objeto del control de constitucionalidad. ${ }^{69}$

En vista de lo anterior, la posible aplicación del principio de jerarquía en los conflictos normativos que digan relación con tratados internacionales dependerá, necesariamente, de la toma de posición respecto de una u otra interpretación de las disposiciones constitucionales.

b) El principio de temporalidad tampoco es apto para dar una solución a este conflicto, toda vez que un tratado puede derogar disposiciones legales, pero no en el sentido inverso. Así, la Constitución establece que: "[las] disposiciones de un tratado sólo podrán ser derogadas, modificadas o suspendidas en la forma prevista en los propios tratados o de acuerdo a las normas generales de derecho internacional” (art. $54, \mathrm{~N}^{\circ} 1$, i. V, CPR). ${ }^{70}$

c) Por último, el criterio de especialidad tampoco contiene los elementos necesarios para dirimir la cuestión, pero por la siguiente razón: los principios clásicos giran en torno a conflictos normativos entre fuentes de un mismo rango, lo que no ocurre entres las leyes y los tratados internacionales.

Es impropio aspirar a resolver conflictos normativos entre tratados internacionales y fuentes nacionales con los principios clásicos. Lo anterior, toda vez que estos preceptos no comparten un mismo rango normativo, puesto que los tratados constituyen una fuente autónoma de derecho. ${ }^{71}$

Para resolver el conflicto, el único criterio que permite entregar una respuesta es el principio de competencia. ${ }^{72}$ Según este, se realiza una distribución de las materias que deben ser reguladas a través de las distintas fuentes formales en el ordenamiento jurídico. De esta forma, la manera de resolver el conflicto entre los diversos preceptos en el sistema jurídico nacional ya no se limita a los criterios clásicos, sino que incluye este principio. ${ }^{73}$

Frente a la aplicación del principio de competencia surgen nuevas interrogantes.

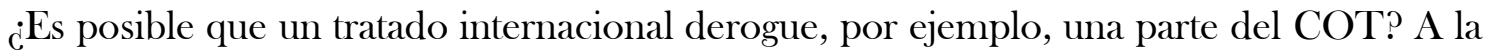
luz de lo anteriormente expuesto, esto es posible: un acuerdo internacional puede derogar una ley, sea ordinaria u orgánica constitucional. Ahora bien, lo relevante es tener en consideración que este efecto no es general, sino que dicha derogación operaría respecto solo de ciertos casos y situaciones previstas por el propio tratado. Por último, el requisito para esta hipótesis viene dado por que se cumpla lo previsto por la Constitución y el tratado sea aprobado con el quórum que corresponda conforme al artículo 66 (art. 54, № 1, i. I, CPR).

\footnotetext{
${ }^{68}$ MÜLleR (2015), pp. 506-508. Asimismo, vid. CuMPLIDO (1996), pp. 255-258.

${ }^{69}$ MÜller (2015), pp. 508-509. En este sentido, vid. RIBERA (2007), pp. 97-115.

${ }^{70}$ Cfr. VARgas (2017), pp. 203-204.

${ }^{71}$ Cordero (2009), p. 46.

${ }^{72}$ BASCUÑ́N (1998), pp. 33-36.

${ }^{73}$ CORDero (2009), pp. 35-36.
} 
A modo ilustrativo, vale tener en consideración algunos ejemplos prácticos en la aprobación de tratados internacionales. Para estos efectos, se recogerán las tramitaciones del ALC suscrito con los Estados Unidos de América y del APPI celebrado con Islandia.

En el primer caso, el instrumento internacional requirió, para su aprobación parlamentaria, contar con el quórum orgánico constitucional, en virtud de que este contenía disposiciones que pugnaban con algunas de las funciones atribuidas al Banco Central de Chile, consagradas en la ley № 18.840. En este sentido, la aplicación del artículo 10.8 del ALC, relativo a transferencias, incide en las facultades del instituto emisor para establecer restricciones a las operaciones internacionales en moneda extranjera. ${ }^{74}$

Por otro lado, en cuanto a la tramitación del tratado de inversión suscrito con Islandia, este instrumento internacional fue adoptado sin la necesidad de contar con un quórum especial para la aprobación parlamentaria. Esto, aun cuando el instrumento consagra la figura del arbitraje de inversiones para la resolución de conflictos entre el inversionista foráneo y el Estado receptor. ${ }^{75}$

En atención a lo expuesto, es plausible sostener dos ideas. Primeramente, un tratado internacional puede modificar disposiciones contenidas en una ley orgánica constitucional, en la medida que cumpla con lo prescrito por la Carta Fundamental y sea aprobado con el quórum requerido, conforme al artículo 66 de la Constitución. En un segundo término, la aprobación de un tratado que importe la obligación internacional del Estado de Chile a someter disputas jurídicas de inversiones al conocimiento de un panel arbitral, no se encuentra sujeta a ningún quórum especial, es decir, en lo pertinente, sigue los trámites de una ley ordinaria.

Finalmente, vale tener en consideración que el arbitraje de inversiones no es el único caso en que un órgano internacional se encarga de cumplir una función jurisdiccional, así como tampoco representa un caso aislado de diálogo entre la jurisdicción nacional e internacional. ${ }^{76}$ Particularmente, es posible advertir el caso en que el Tribunal Constitucional (TC) debió pronunciarse acerca de la constitucionalidad de las competencias que le fueron conferidas a la Corte Penal Internacional, en virtud del Estatuto de Roma. Se alegó, entre otras cosas, que el Estatuto violaba la soberanía nacional, al posibilitar la renuncia a la potestad de administrar justicia que corresponde a todo Estado independiente. ${ }^{77}$

Frente a esto, el $\mathrm{TC}^{78}$ consideró que, para que se pudiese reconocer jurisdicción a un tribunal supranacional, era necesario que este se incorporase dentro del sistema nacional debiéndose, previamente, modificar el texto constitucional. Esto se materializó

\footnotetext{
${ }^{74}$ Biblioteca del Congreso Nacional (2003), pp. 48, 190, 324, 332 y 372-373.

${ }^{75}$ Biblioteca del Congreso Nacional (2006), pp. 7, 9 y 17.

${ }^{76}$ Vale destacar otras situaciones de diálogo e interrelación entre la jurisdicción nacional e internacional, como, por ejemplo, los casos en que la Corte Suprema ha debido pronunciarse acerca de la extensión de los efectos de las sentencias dictadas por la Corte Interamericana de Derechos Humanos (CIDH) dentro del control de convencionalidad. Para una revisión del control de convencionalidad y del diálogo jurisprudencial vid. NASH (2013), pp. 491-499 y 502-506; CAMARILLO y ROSAS (2016), pp. 134-140, 142-144 y 153-158 y Olano (2016), pp. 63-83. Asimismo, un comentario de este diálogo, a propósito del caso "Atala Riffo y niñas vs. Chile”, puede ser revisado en ZUÑIGA (2012), pp. 430-467.
}

${ }^{77}$ VARGAS (2017), pp. 626-628.

${ }^{78}$ Requerimiento de inconstitucionalidad presentado por un grupo de Diputados respecto del Estatuto de Roma de la Corte Penal Internacional (2002). 
con la ley № 20.352 y la incorporación de la disposición transitoria vigesimocuarta en la Constitución.

Por último, cabe preguntarse por qué esta situación no se ha replicado en el caso de los APPI y ALC. Como se ha dicho, los tribunales arbitrales ejercen una función jurisdiccional, pero para la ratificación de dichos tratados no ha sido necesario reformar continuamente la Constitución. A partir de un análisis de la sentencia en comento, parece ser que la respuesta viene dada por el considerando quincuagésimo, en cuanto el TC establece que "todo conflicto en cuya solución exista un interés público comprometido, queda necesariamente sometido al conocimiento y decisión de los tribunales establecidos por la ley (formal) chilena"; por otro lado, aquellos que se refieran a derechos disponibles, podrán prorrogarse entre tribunales nacionales e internacionales. De esta forma, a la luz de la tramitación de los APPI, parece meridianamente claro que, para el TC, los conflictos de inversión extranjera dicen relación con derechos disponibles.

\section{CONCLUSIONES}

Es posible afirmar que el arbitraje internacional de inversiones importa una actividad jurisdiccional, toda vez que este agota el componente jurídico de un especial conflicto (de inversiones), entre unos especiales sujetos (Estados soberanos e inversores privados). El anterior agotamiento, se entiende tanto desde la perspectiva de la cosa juzgada, como desde la posibilidad de la aplicación de coacción, a fin de concretar la decisión del tribunal arbitral.

Dentro del esquema de la jurisdicción chilena, la Constitución Política de la República no toma partido por la naturaleza de los órganos llamados a cumplir dicha función, limitándose a indicar que esta debe llevarse a cabo por los tribunales establecidos por la ley.

$\mathrm{El}$ arbitraje internacional de inversiones no viene establecido por la ley, sino por los tratados internacionales suscritos y ratificados por Chile. Si bien es posible afirmar que no son tribunales de conformidad a la ley chilena, lo cierto es que el arbitraje de inversiones desarrolla una función jurisdiccional: los paneles arbitrales internacionales conocen de unos conflictos, siguen un procedimiento específico y fallan. Asimismo, sus laudos tienen unos efectos obligatorios específicos respecto de aquellos sujetos que concurren a él.

La cuestión de la incorporación del arbitraje de inversiones, a través de los tratados internacionales en materia de inversión, debe ser analizada a la luz los conflictos normativos en el sistema jurídico. A partir de dicho análisis, es posible concluir que la respuesta viene dada por la aplicación del principio de competencia en las antinomias.

Malamente podría afirmarse que el arbitraje internacional de inversiones importa una novedad. La historia del derecho indica todo lo contrario. En el medioevo europeo ya existía una suerte de tribunales especiales, amparados por el poder político, que tenían por objeto cumplir con la función jurisdiccional en un ámbito especial, que era el comercio. Es posible afirmar que hoy se ha revitalizado dicha visión y que este mecanismo de resolución de controversias ha sido la respuesta institucional a unos especiales conflictos que tienen lugar en el concierto internacional actual; lo anterior, en atención a la globalización y al aumento de los vínculos comerciales y económicos entre los Estados y distintos sujetos. 


\section{BIBLIOGRAFÍA CITADA}

Aldunate, Eduardo (1995). "La independencia judicial. Aproximación teórica. Consagración constitucional y crítica”, Revista de Derecho de la Pontificia Universidad Católica de Valparaíso, № 16, pp. 11-26.

Aldunate, Eduardo (2002). "Reformulación de las reglas o elementos de interpretación para una práctica de la interpretación constitucional”, Revista de Derecho de la Universidad de Piura, Vol. 3, pp. 259-273.

Aldunate, Eduardo (2010). "La posición de los tratados internacionales en el sistema de fuentes del ordenamiento jurídico chileno a la luz del derecho positivo”, Revista Ius et Praxis, Año 16, № 2, pp. 185-210.

ATRIA, Fernando (2004). "Jurisdicción e independencia judicial: El Poder Judicial como poder nulo”, Revista de Estudios de la Justicia, № 5, pp. 119-141.

BiggS, Gonzalo (2007). "La institucionalidad chilena y el arbitraje internacional”, en PiCAND, Eduardo (coord.), Estudios de arbitraje: libro homenaje al profesor Patricio Aylwin Azócar (Editorial Jurídica de Chile), pp. 351-376.

BASCUÑán, Antonio (1998). "El principio de la distribución de competencia como criterio de solución de conflictos de normas jurídicas”, Revista Chilena de Derecho, Vol. 25, № 1 , pp. 33-44.

Biblioteca Del Congreso Nacional (2003): "Historia del Decreto № 312", en: https://www.bcn.cl/historiadelalev/nc/historia-de-la-lev/5517/

Biblioteca Del Congreso Nacional (2006): "Historia del Decreto № 186", en: https:/www.bcn.cl/historiadelaley/nc/historia-de-la-ley/5192/

Böckenförde, Ernst-Wolfgang (1991). State, Society and Liberty (trad. James Amery Underwood, Berg Publishers Limited).

BORDALí, Andrés (2008). "La doctrina de la separación de poderes y el Poder Judicial chileno”, Revista de Derecho de la Pontificia Universidad Católica, № 30, pp. 185219.

Bordalí, Andrés (2009). "Organización judicial en el derecho chileno: Un poder fragmentado", Revista Chilena de Derecho, Vol. 36, № 2, pp. 215-244.

BORDALí, Andrés (2013). "La independencia de los jueces en la aplicación de la ley dentro de la organización judicial chilena”, Revista Chilena de Derecho, Vol. 40, № 2, pp. 609-634.

Bordalí, Andrés (2016). Derecho jurisdiccional (Ediciones Universidad Austral de Chile).

Brownlie, Ian (2008). Principles of Public International Law (Oxford University Press, $7^{\mathrm{a}}$ ed.).

Bungenberg, Marc y Reinisch, August (2020). From Bilateral Arbitral Tribunals and Investment Courts to a Multilateral Investment Court. Options Regarding the Institutionalization of Investor-State Dispute Settlement (Springer, 2를.).

Camarillo, Laura y Rosas, Nataly (2012). "El control de convencionalidad como consecuencia de las decisiones judiciales de la Corte Interamericana de Derechos”, Revista IIDH, Vol. 64, pp. 127-159. 
Campusano, Raúl y Bolado, Álvaro (2015). "Algunas reflexiones en torno a la participación de Chile en el Centro Internacional de Arreglo de Diferencias Relativas a Inversiones, CIADI”, Revista Actualidad Jurídica, № 32, pp. 245-279.

CARrillo, Juan José (2010). "El neoliberalismo en Chile: entre la legalidad y la legitimidad. Entrevista a Tomás Moulián”, Perfiles Latinoamericanos, Vol. 18, № 35, pp. 145155.

Colombo, Juan (1968). "La jurisdicción en el derecho chileno”, Anales de la Facultad de Ciencias Jurídicas y Sociales, Vol. 8, № 8, en: https://revistas.uchile.cl/index.php/ACJYS/issue/view/1038

Comisión Económica para América latina y el CARibe (CEPAL) (2021): "La Inversión Extranjera Directa en América Latina y el Caribe 2021”, en: https://repositorio.cepal.org/bitstream/handle/11362/47147/3/S2100319_es.pdf

Cordero, Eduardo (2009). "Los principios y reglas que estructura el ordenamiento jurídico chileno”, Revista Ius et Praxis, Año 15, № 2, pp. 11-49.

Cumplido, Francisco (1996). "Alcances de la modificación del artículo $5^{\text {o }}$ de la Constitución Política chilena en relación a los tratados internacionales”, Revista Chilena de Derecho, Vol. 23, №s 2 y 3, Tomo I, pp. 255-258.

Diez de Velasco, Manuel (2017). Instituciones de Derecho Internacional Público (Tecnos, $16^{\mathrm{a}}$ ed.).

Dolzer, Rudolf y Schreuer, Christoph (2008). Principles of International Investment Law (Oxford University Press).

Domingo, Rafael (2008). ¿Qué es el Derecho Global? (Thomson Reuters Arazandi, 6ª ed.).

Fernández, José Carlos (2009). "América Latina y el arbitraje de inversiones: ¿Matrimonio de amor o matrimonio de conveniencia?”, Revista de la Corte Española de Arbitraje, Vol. 24, pp. 13-37.

Ferrer, Maria Teresa (1999). "El Consolat de Mar i els Consolats d'Ultramar, Instruments i manifestació de l'expansió del comerç catalá”, en Ferrer, Maria Teresa y Coulon, Damien (coords.), L'Expansió Catalana a la Mediterrània a la Baixa Edat Mitjana (Consejo Superior de Investigaciones Científicas), pp. 53-79.

Guerrero, José Luis (2021). “El arbitraje de inversiones en Chile”, en EsPlugues, Carlos y Guerrero, José Luis (edits.), Derecho del Comercio Internacional Chileno (Tirant Lo Blanch), pp. 539-556.

GuZMán, Alejandro (1992). "La historia dogmática de las normas sobre interpretación recibidas por el Código Civil de Chile” en Universidad de Chile \& UNIVERSIDAD AdOLFO IBAÑEZ, Interpretación, Integración y Razonamiento Jurídico (Editorial Jurídica de Chile), pp. 41-87.

Guzmán, Alejandro (2013). Derecho Privado Romano. Tomo I (LegalPublishing/Thomson Reuters).

Harvey, David (2005). Brief History of Neoliberalism (Oxford University Press).

Henríquez, Miriam Lorena (2008). "Jerarquía de los tratados de derechos humanos: análisis jurisprudencial desde el método de casos”, Estudios Constitucionales, Año 6, № 2, pp. 73-119.

HobBes, Thomas (1999). Leviatán (Publicaciones Cruz O.S.A.). 
Huesbe, Marco Antonio (1995). "La jurisdicción como atributo de la soberanía. El derecho de apelación en última instancia o 'jus in extrema provocatione' y la concesión de la gracia en el Estado moderno", Revista de Estudios HistóricoJurídicos, № 17, pp. 337-358.

Huneeus, Carlos (2007). The Pinochet Regime (trad. Lake Sagaris, Lynne Rienner Publishers).

Larraín, Felipe y Vergara, Rodrigo (2010). La transformación económica de Chile (Centro de Estudios Públicos, 2aㅡ ed.).

LARROUCAU, Jorge (2020). Judicatura (DER Ediciones).

LIM, Chin Leng; Ho, Jean y PAPARINSKIS, Martins (2018). International Investment Law and Arbitration: Commentary, Awards and other Materials (Cambridge University Press).

LOPEANDíA, Felipe (2001). Informe Marco Jurídico Nacional e Internacional sobre Inversión Extranjera Directa en Chile (CEPAL).

Mahu, Pablo y Rojas, Maximiliano (2016). Arbitraje de inversiones. Los casos chilenos ante el CIADI (2003-2015) (Editorial Jurídica AREMI).

Marongiu, Antonio (1953). "Un momento típico de la Monarquía medieval: el Rey juez”, Anuario de Historia del Derecho Español, № 23, pp. 677-716.

Martínez, Faustino (2010). "Ecos cronísticos del Rey-Juez medieval”, Cuadernos de Historia del Derecho, Vol. Extraordinario, pp. 303-356.

Mereminskaya, Elina (2006). "Arbitraje doméstico e internacional en Chile: en búsqueda de la armonía”, en VARGas, J. E. y Gorrión, F. J. (coords.), Arbitraje y Mediación en las Américas (Centro de Estudios de Justicia de las Américas, Universidad Autónoma de Nuevo León), pp. 97-113.

Mereminskaya, Elina (2010). "Demandas contractuales ante los tribunales internacionales a la luz de los APPIS suscritos por Chile”, Sociedad Chilena de Derecho Internacional (Estudios), pp. 37-64.

Merryman, John Henry (1980). La tradición jurídica romano-canónica (trad. Carlos Sierra, Fondo de Cultura Económica).

Miralles de IMPERIAL, Júlia (2017). "El Consolat de Mar, una institución iusprivativista en el mediterráneo medieval”, Revista Electrónica del Instituto de Investigaciones Ambrosio L. Gioja, № 18, pp. 54-70.

MonTt, Santiago (2005). “Aplicación de los tratados bilaterales de protección de inversiones por tribunales chilenos. Responsabilidad del estado y expropiaciones regulatorias en un mundo crecientemente globalizado", Revista Chilena de Derecho, Vol. 32, № 1, pp. 19-78.

MujICA, Ignacio y Rivera, Eugenio (2018). Estudio sobre acuerdos comerciales internacionales y derechos humanos en Chile (Instituto Nacional de Derechos Humanos).

MülleR, Karl (2015). "Transferencia de atribuciones soberanas a organizaciones internacionales en el derecho chileno", Revista de Derecho de la Pontificia Universidad Católica de Valparaíso, № 44, pp. 493-529. 
NASH, Claudio (2013). "Control de convencionalidad. Precisiones conceptuales y desafíos a la luz de la jurisprudencia de la Corte Interamericana de Derechos Humanos”, Anuario de Derecho Constitucional Latinoamericano, Año 19, pp. 489-509.

Olano, Hernán (2016). "Teoría del control de convencionalidad”, Estudios Constitucionales, Año 14, № 1, pp. 61-94.

Pascual-Vives, Francisco (2019). La legitimación activa del individuo en el arbitraje de inversión (Thomson Reuters - Aranzadi).

Pastor, José (2013). Curso de Derecho Internacional Público y Organizaciones Internacionales (Tecnos, $17^{\mathrm{a}}$ ed.).

RibERA, Teodoro (2007). "Los tratados internacionales y su control a posteriori por el Tribunal Constitucional”, Estudios Constitucionales, Vol. 5, № 1, pp. 89-118.

SHAw, Malcolm (2008). International Law (Cambridge University Press, $6^{\underline{a}}$ ed.).

SOLDANI, Maria Elisa y TANZINI, Lorenzo (2016). “Corporaciones y tribunales mercantiles entre Toscana y Cataluña en torno al siglo XIV, Hispania, Vol. 76, № 252, pp. 936.

SORNARAJAH, Muthucumaraswamy (2010). The International Law on Foreign Investment (Cambridge University Press, $3^{\underline{a}}$ ed.).

Subsecretaría de Relaciones Económicas Internacionales (2021): “Acuerdos Comerciales Vigentes", en: https:/www.subrei.gob.cl/acuerdos-comerciales

Tamburini, Francesco (2002). "Historia y destino de la 'Doctrina Calvo': ¿Actualidad u obsolescencia del pensamiento de Carlos Calvo?”, Revista de Estudios HistóricoJurídicos, № 24, pp. 81-101.

VARGas, Edmundo (2017). Derecho Internacional Público (El Jurista, 2a ed.).

VÁsQuEZ, María Fernanda (2005). "La nueva ley de arbitraje comercial internacional de Chile y su análisis comparativo con la ley española”, Revista de Derecho de la Pontificia Universidad Católica de Valparaíso, Vol. 26, № 2, pp. 533-558.

ZúÑIGA, Francisco (2012). "Comentario a la sentencia de la Corte Interamericana de Derechos Humanos, caso 'Atala Riffo y niñas vs. Chile’ de 24 de febrero de 2012”, Estudios Constitucionales, Año 10, № 1, pp. 429-468. 


\section{JURISPRUDENCIA CITADA}

Chile:

Requerimiento de inconstitucionalidad presentado por un grupo de Diputados respecto del Estatuto de Roma de la Corte Penal Internacional, adoptado en dicha ciudad el 17 de julio de 1998 (2002). Tribunal Constitucional, 8 de abril de 2002, Rol № 346-02. 


\section{NORMAS CITADAS}

Chile:

Constitución Política de la República de 1980 (CPR).

Código Civil de 1857 (CC).

Código de Procedimiento Civil de 1902 (CPC).

Código Orgánico de Tribunales de 1953 (COT).

Decreto ley № 600 del 13 de julio de 1974, Estatuto de la inversión extranjera.

Ley № 18.840 del 10 de octubre de 1989, Ley orgánica constitucional del Banco Central de Chile.

Ley № 20.848 del 25 de junio de 2015, Establece marco para la inversión extranjera en Chile y crea la institucionalidad respectiva.

\section{Tratados internacionales:}

Convención de las Naciones Unidas sobre el Reconocimiento y la Ejecución de las Sentencias Arbitrales Extranjeras de 1958.

Convenio sobre Arreglo de Diferencias relativas a Inversiones entre Estados y Nacionales de otros Estados de 1965 (Convenio CIADI).

Convención de Viena sobre el Derecho de los Tratados (Convención de Viena) de 1969.

Acuerdo entre la República de Chile y el Reino de España para la Protección y Fomento Recíprocos de Inversiones de 1991 (APPI Chile - España).

Convenio entre el Gobierno de la República de Chile y el Gobierno de la República de Francia sobre la Promoción y Protección Recíprocas de Inversiones de 1992 (APPI Chile - Francia).

Acuerdo entre el Gobierno de la República de Chile y el Gobierno de la República de Italia sobre Promoción y Protección de las Inversiones de 1993 (APPI Chile - Italia).

Tratado de Libre Comercio entre el Gobierno de la República de Chile y el Gobierno de los Estados Unidos Mexicanos de 1998 (ALC Chile - México).

Convenio entre el Gobierno de la República de Chile y el Gobierno de la República de Islandia para la Promoción y Protección Recíproca de las Inversiones de 2003 (APPI Chile - Islandia).

Tratado de Libre Comercio entre el Gobierno de la República de Chile y el Gobierno de los Estados Unidos de América de 2003 (ALC Chile - Estados Unidos). 